\title{
Measurement of Tissue Pressure in the Dental Pulp, using a Servo-Controlled Counterpressure System, of the Rat Incisor
}

\author{
Akemi Shimada, Koichiro Komatsu* and Mototsugu Chiba \\ Department of Pharmacology, Tsurumi University School of Dental Medicine 2-1-3 Tsurumi, Tsurumi-ku, Yokohama, 230-8501, Japan
}

*Corresponding author: Koichiro Komatsu, Department of Pharmacology, Tsurumi University School of Dental Medicine 2-1-3

Tsurumi, Tsurumi-ku, Yokohama, 230-8501, Japan

\section{ARTICLE INFO}

Received: 幽 December 03, 2019

Published: 彗 December 19, 2019

Citation: Akemi Shimada, Koichiro Komatsu, Mototsugu Chiba. Measurement of Tissue Pressure in the Dental Pulp, using a Servo-Controlled Counterpressure System, of the Rat Incisor. Biomed J Sci \& Tech Res 24(1)-2019. BJSTR. MS.ID.003991.

Keywords: Servo-Controlled Counterpressure System; Tissue Pressure; Dental Pulp; Tooth Movement; Experimental Animals

\section{ABSTRACT}

The measurement of the regional blood flow in rat teeth following injections of hypotensive and hypertensive drugs provided interesting information on the relationship between the movement and the vasculature of the tooth. However, few of measurement of the tissue pressure in the tooth were yet done in relation to the tooth movement. Here, we applied a servo-controlled counterpressure system to measure the tissue pressure in the rat incisor combined with measurement of the regional blood flow and axial tooth movement following injection of vasopressin under anesthesia. To insert a sharpened glass micropipette for measurement of the tissue pressure through the alveolar bone into the dental pulp, the exposed bone at the base of the incisor was regionally decalcified. After a stable pressure was observed for $5 \mathrm{~min}$, the tip of the micropipette was inserted into the socket through the decalcified site under a stereomicroscope. When a pressure reading with a steady small oscillation for $5 \mathrm{~min}$ was obtained as the control, various doses of injections of vasopressin were performed. Measurement of the tissue pressure in the dental pulp obtained here was satisfactorily reliable; the tissue pressure exhibited expectedly decreased values following the injections of vasopressin in a dose-dependent manner. The changes in the axial tooth movement were intimately related to the changes in the tissue pressure and blood flow in the dental pulp. Thus, the measurement of the tissue pressure in and around teeth is very useful to investigate into the relationship between the movement and the vasculature of the tooth.

\section{Introduction}

Several earlier studies have suggested that the positions of teeth in experimental animals and humans may be influenced by vascular forces, probably due to changes in the regional blood flow, vascular pressure, or pulsatile forces in and around the teeth [1-3]. We previously found that local injections of hypotensive and hypotensive drugs caused increases and decreases of the blood flow within the socket, respectively [4-6]. The increased and decreased blood flows are probably caused by vasodilatation and by vasoconstrictions, respectively [4-6]. Since the dental pulp resides in a low-compliance environment, an increase in blood flow, or precapillary vasodilatation, and a decrease in blood flow, or vasoconstriction, will be accompanied by a rise and a reduction in tissue pressure, respectively
[7]. Thus, these increases and decrease of the regional blood flow within the tooth socket might have caused an increase and a decrease of the tissue pressure, resulting in the extrusive and intrusive movements of the rat incisor, respectively [4-6].

Tissue pressure, or interstitial fluid pressure, is the hydrostatic pressure in the potential free fluid of the interstitium in the tissue 8. The tissue pressure and blood flow within the socket under various experimental conditions have been extensively reported [7-12]. The tissue pressure in and around the tooth may be one of the motive forces of axial tooth movements [13-15]. However, only a few studies have recorded the tissue pressure within the tooth socket in relation to the tooth movement [9]. The aim of the present 
study was to apply a servo-controlled counterpressure system, a reliable method for measurement of tissue pressure, to measure the tissue pressure in the rat incisor combined with measurement of the regional blood flow and axial tooth movement following injection of vasopressin under anesthesia.

\section{Materials and Methods}

\section{Animal Preparation and Administration of Vasopressin}

All animal experiments were approved by the Institutional Animal Care Committee of Tsurumi University School of Dental Medicine. The rats were anesthetized, as described previously [15]. A polyurethane tube $(0.84 \mathrm{~mm}$ in diameter $)$ was inserted into the left femoral vein. Through this tube, $0,0.005,0.05$, and $0.5 \mathrm{U}$ of vasopressin (Pitressin ${ }^{\circledR}$ Inj., Sankyo, Tokyo, Japan) dissolved in $1 \mathrm{ml}$ of Ringer's solution was serially injected in the order of lower to higher doses at a volume of $1 \mathrm{~mL} / \mathrm{kg}$ body weight of the animal.

\section{Measurements of Axial Tooth Movement, and Regional Blood Flow}

The axial movement of the mandibular incisor was measured as described previously [15]. The axial tooth movement per minute and the eruption rate $(\mu \mathrm{m} / \mathrm{min})$ were calculated. The mean blood pressure was measured using a pressure transducer via a polyurethane tube inserted into the right femoral artery. Regional blood flow at the base of the incisor was measured using a laser Doppler flowmeter as described previously [4,16]. Briefly, to prepare for the measurement, a part of the bone surface at the base of the incisor was surgically exposed, the remaining muscles surrounding the exposed bone were excluded by a polyethylene ring (exclusion ring), and the tip of a needle-type probe (BN-0.5, Bio Research Center) from the flowmeter was then placed close to the exposed bone surface (Figure 1). The blood flow was represented as the relative value of $\mathrm{mV}$. Figures $2 \mathrm{a} \& 2 \mathrm{~b}$ show the approximate area used to measure the regional blood flow.

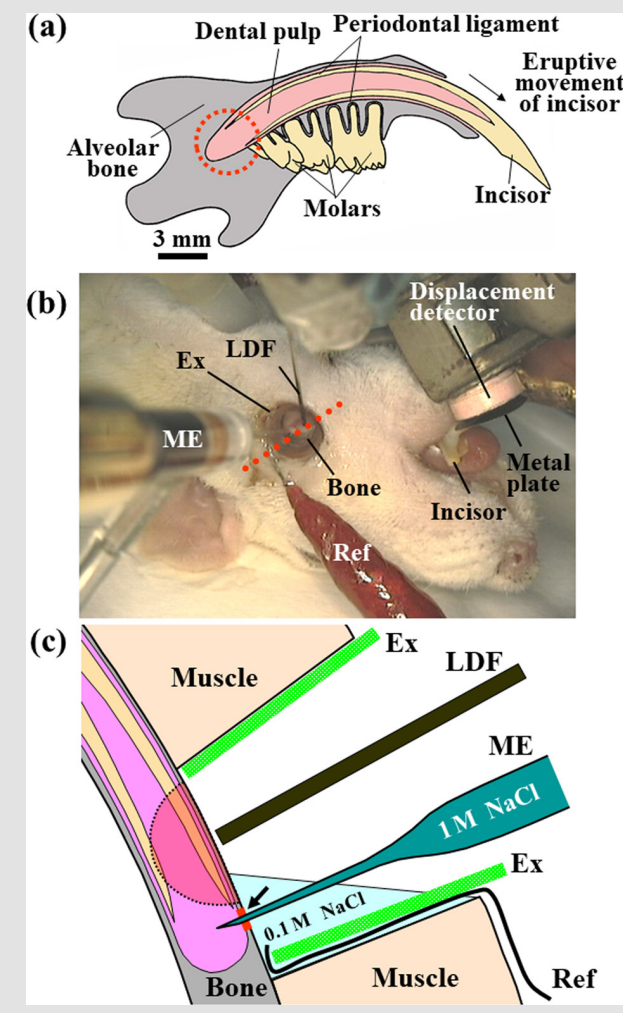

Figure 1:

a) Schematic representation of rat mandible seen on the labial side in the supine position. The axial eruptive movement of the incisor, the tissue pressure, and the regional blood flow within the socket (dotted circle) were simultaneously recorded.

b) Experimental setup [7]. The axial eruptive movement (a) of the mandibular incisor was measured with a displacement detector and a metal plate attached to the tooth surface under anesthesia. To measure the regional blood flow and tissue pressure, a part of the mandibular bone surface at the base of the incisor was surgically exposed. The remaining muscles surrounding the exposed bone were excluded with a polyethylene ring (exclusion ring, EX).

c) Schematic representation of a transverse section cut through an axis (red dotted line, (b)) [9]. The regional blood flow was measured by a laser Doppler flowmeter over the exposed mandibular bone. To measure the tissue pressure, a microelectrode filled with $1 \mathrm{M} \mathrm{NaCl}$ was immersed into a solution of $0.1 \mathrm{M} \mathrm{NaCl}$ in a space of excluded muscles to adjust the pressure in the microelectrode to $0 \mathrm{mmHg}$ and was then inserted into the socket through a bone site (arrow) decalcified by an etching reagent. A ground reference electrode (Ref) was placed in the solution of $0.1 \mathrm{M} \mathrm{NaCl}$. An arc with a radius of $1 \mathrm{~mm}$, as indicated by the dotted line, show the approximate area where the blood flow could be measured. LDF, a probe from the laser Doppler flowmeter; ME, microelectrode. 

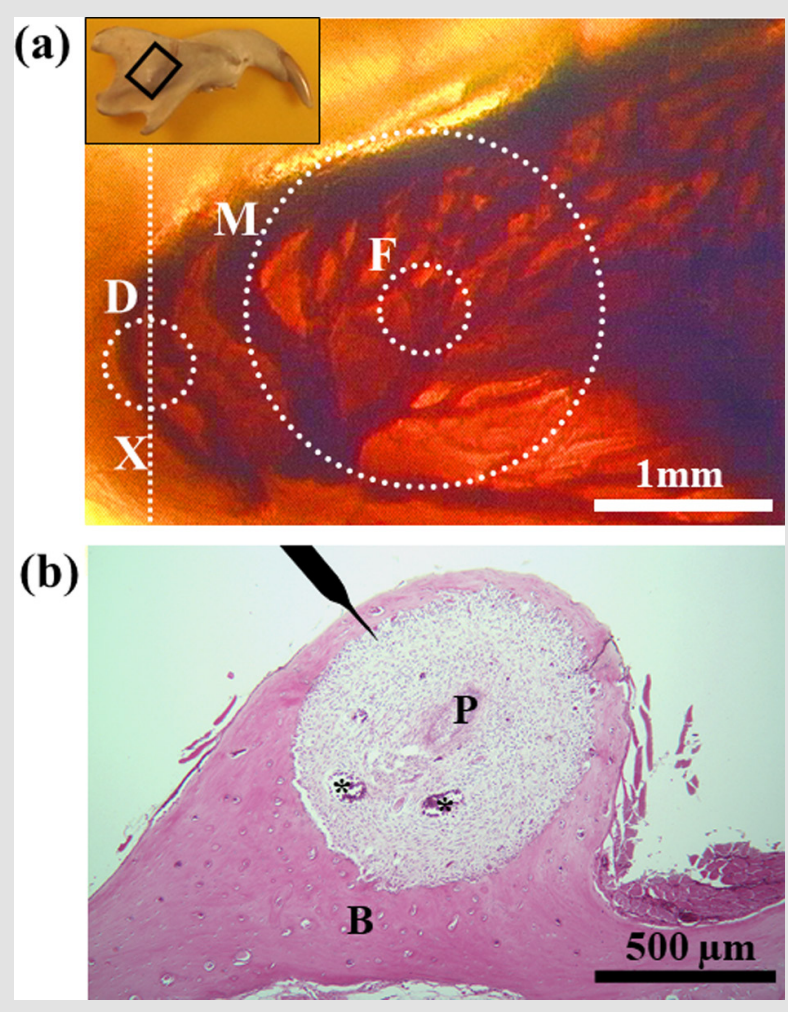

Figure 2:

a) Plastic-embedded thick sagittal unstained section of the rat mandibular incisor showing vasculature within the socket of the basal part of the tooth. Transmitted light. Inset, Diagram of rat mandible in the supine position. The framed square indicates the area magnified in Figure 2(a). The dotted circles and line indicate approximate areas where the bone was decalcified to measure the tissue pressure (D), where the probe from the laser Doppler flowmeter was applied (F), and where the blood flow could be measured (M).

b) Hematoxylin and eosin-stained section cut transversely through an axis (Figure $2 \mathrm{a}, \mathrm{X}$ ) showing the site where the tissue pressure was measured. The position of the microelectrode to measure the tissue pressure is shown on top. Asterisks indicate large blood vessels. P, dental pulp; B, alveolar bone.

\section{Measuremen of Tissue Pressure in the Dental Pulp}

To insert a smoothly sharpened glass microelectrode for measurement of the tissue pressure through the alveolar bone into the dental pulp, a part of the exposed bone at the base of the incisor, with an approximate area diameter of $0.5 \mathrm{~mm}$, was regionally decalcified by an etching reagent (K-etchant, Kuraray Co., Ltd., Okayama, Japan) for 30min (Figures 1b \& 2a) under a digital microscope (VH-5910, KEYENCE, Osaka, Japan) equipped with a zoom lens (VH-Z05, KEYENCE). The measurements of the tissue pressure were performed with the glass microelectrode with tip diameters of 4 to $6 \mu \mathrm{m}$, filled with $1 \mathrm{M} \mathrm{NaCl}$. The microelectrode mounted on a micromanipulator was connected to a servo-controlled counter pressure system (900A Micropressure System, World Precision Instrument, Inc., FL, USA). The tip of the microelectrode was first immersed in a solution of $0.1 \mathrm{M} \mathrm{NaCl}$ in a space of excluded muscle (Figure $1 \mathrm{~b}$ ) to adjust the pressure value in the microelectrode to $0 \mathrm{mmHg}$. After a stable pressure value without oscillation was observed for $5 \mathrm{~min}$, the tip of the microelectrode was inserted into the socket through the decalcified site using the digital microscope. When the mean value of a pressure reading with a steady small oscillation (within a few $\mathrm{mmHg}$ ) for more than $5 \mathrm{~min}$ was obtained as the control tissue pressure, the injections of vasopressin were performed. The resulting data were downloaded onto a computer (Macintosh PowerBook, Apple Japan, Inc., Tokyo, Japan) by an analog-digital converter (MacLab, ADInstruments Japan Inc., Nagoya, Japan) at intervals of $0.5 \mathrm{~s}$ and were reconstructed at intervals of $6 \mathrm{~s}$.

\section{Statistics}

Twenty male Wistar rats were used. The measurements and anesthesia failed in six rats. Thus, fourteen rats, weighing $398 \pm 32$ (SD) g and aged $120 \pm 18$ days, were used for data analysis. When the tissue pressure showed a drift and/or a large oscillation in the pressure reading, all of the blood pressure, blood flow, and tooth movement data related to those measurements of tissue pressure were excluded. Following the injection of the various doses of vasopressin, four measurements, such as the maximum value of the mean blood pressure, the minimum value of the blood flow, the minimum value of the tissue pressure, and the minimum value of the eruption rate, were determined. Regression analyses were used to examine the relationships between the log-dose of vasopressin 
and each of the four measures and between any two of the four measures. Significant differences between correlation coefficients and zero were examined by Student's t-test.

\section{Results}

Changes in the regional blood flow, and the tissue pressure in the dental pulp after various doses of vasopressin

Following the injections of $0.005,0.05$, and $0.5 \mathrm{U} / \mathrm{kg}$ of vasopressin, the blood pressure and the regional blood flow transiently increased (Figure 3a, Suppl. Figure 1Sa) and expectedly decreased, respectively, in a dose-dependent manner (Figure $3 \mathrm{~b}$,
Suppl. Figure 1Sb). Following the injections of $0.005,0.05$, and $0.5 \mathrm{U} / \mathrm{kg}$ of vasopressin, the tissue pressure decreased in a dosedependent manner (Figure 3c); the mean tissue pressure decreased from $17.1 \pm 9.0(\mathrm{SD})$ to $15.7 \pm 8.4,11.8 \pm 7.5$, and $10.6 \pm 8.6 \mathrm{mmHg}$, respectively (Suppl. Figure 1Sc). The effects of the injection of Ringer's solution $(0 \mathrm{U} / \mathrm{kg})$ on the blood pressure, blood flow, and tissue pressure were not marked. The blood pressure, blood flow and tissue pressure returned essentially to their basal levels in approximately $15 \mathrm{~min}$ after 0.005 and $0.05 \mathrm{U} / \mathrm{kg}$ of vasopressin but did not reach to their basal levels for some rats in 20 min after 0.5 $\mathrm{U} / \mathrm{kg}$ of vasopressin.

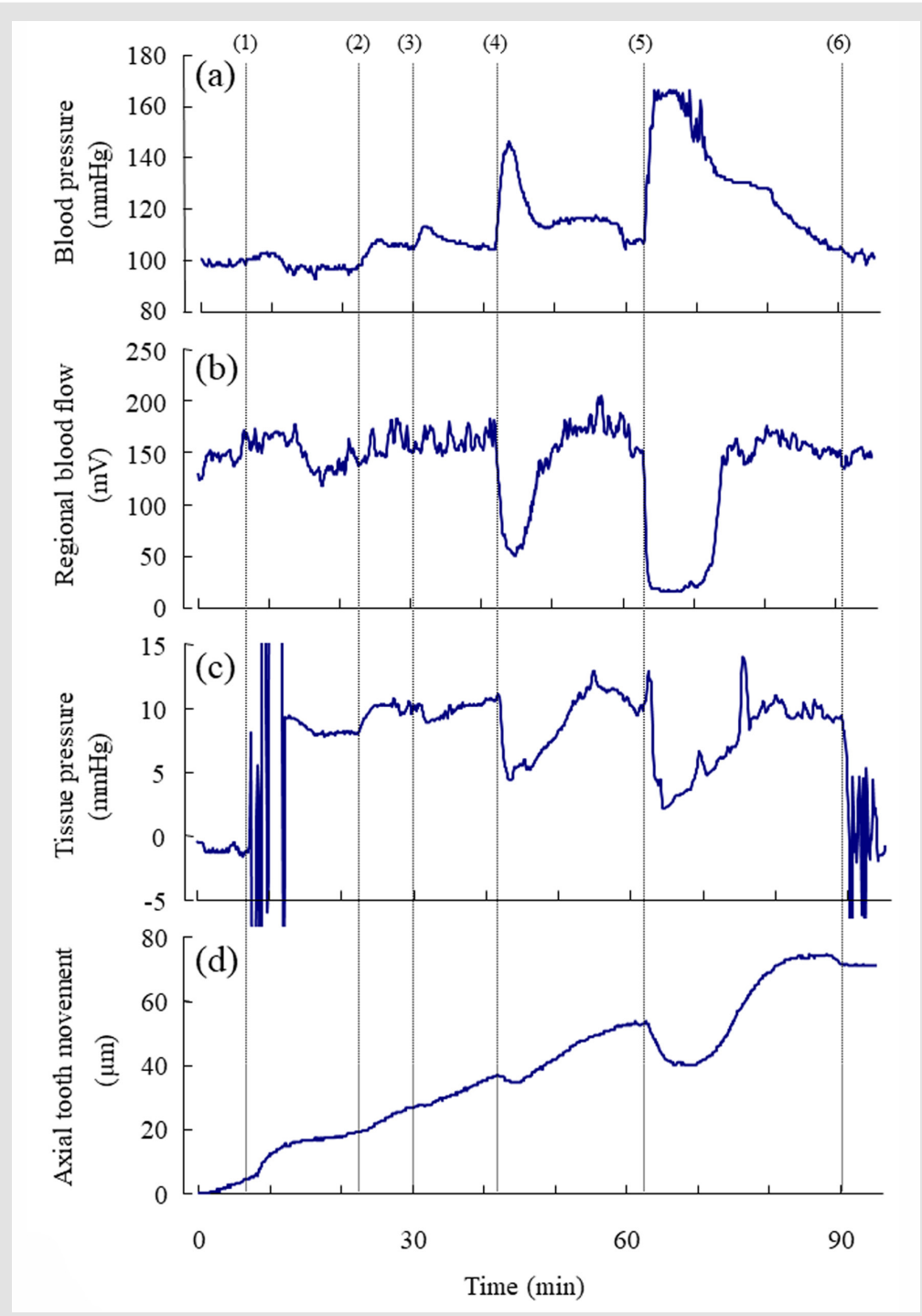

Figure 3: Representative example of the simultaneous recording of

a) the mean arterial blood pressure $(\mathrm{mmHg})$,

b) the regional blood flow $(\mathrm{mV})$ at the base of the incisor,

c) the tissue pressure $(\mathrm{mmHg})$ at the base of the incisor, and

d) the axial tooth movement $(\mu \mathrm{m})$ following the injections of vasopressin.

Number (1) indicates the insertion of the microelectrode into the dental pulp for measurement of tissue pressure. Numbers (2), (3), (4), and (5) indicate the starts of the injections of $0,0.005,0.05$, and $0.5 \mathrm{U} / \mathrm{kg}$ of vasopressin, respectively. Number (6) indicate the removal of the electrode from the tissue. Each point represents the mean value $(n=8 \sim 14)$ at intervals of $6 \mathrm{~s}$. 


\section{Changes in the Axial Tooth Movement after Various Doses of Vasopressin}

The mean rate of the extrusive tooth movement before the injection of various doses of vasopressin was $2.9 \pm 1.3$ (SD) $\mu \mathrm{m} / 5 \mathrm{~min}$ $(845 \pm 382 \mu \mathrm{m} / 24 \mathrm{~h})$. Following the injections of $0.005,0.05$, and $0.5 \mathrm{U} / \mathrm{kg}$ of vasopressin, intrusive tooth movements were observed in a dose- dependent manner (Figure 3d, Suppl. Figure1Sd), and the rates of axial tooth movements were $-0.4 \pm 0.9(\mathrm{SD}),-1.3 \pm 1.0$, and $-3.9 \pm 2.2 \mu \mathrm{m} / \mathrm{min}$ (Suppl. Figure 1Se), respectively. Negative correlations were found between the log-dose of vasopressin and the minimum value of the blood flow (Figure $4 \mathrm{~b} ; \mathrm{r}=-0.898$, $\mathrm{p}<0.001$ ), between the log-dose of vasopressin and the minimum value of the tissue pressure (Figure $4 c ; r=-0.607, p<0.01$ ), and between the log-dose of vasopressin and the minimum rate of extrusive tooth movement (Figure $4 \mathrm{~d} ; \mathrm{r}=-0.753, \mathrm{p}<0.001$ ). There are positive correlations between the blood flow and the tissue pressure (Figure 5a), between the blood flow and the extrusive tooth movement (Figure $5 \mathrm{~b}$ ), and between the tissue pressure and the extrusive tooth movement (Figure 5c), following the injections of various doses of vasopressin. Positive correlations were found between all the pairs, and all the correlation coefficients were significantly different from zero $(\mathrm{p}<0.05 \sim 0.01)$.

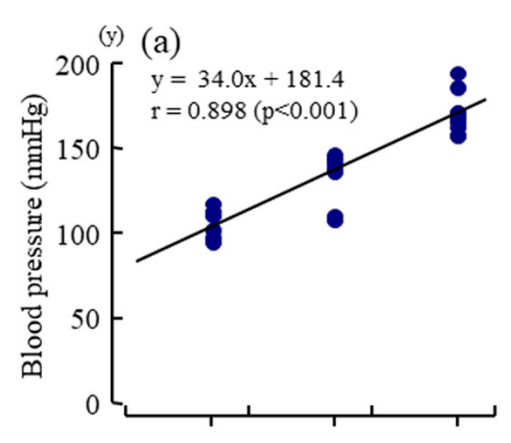

(c)

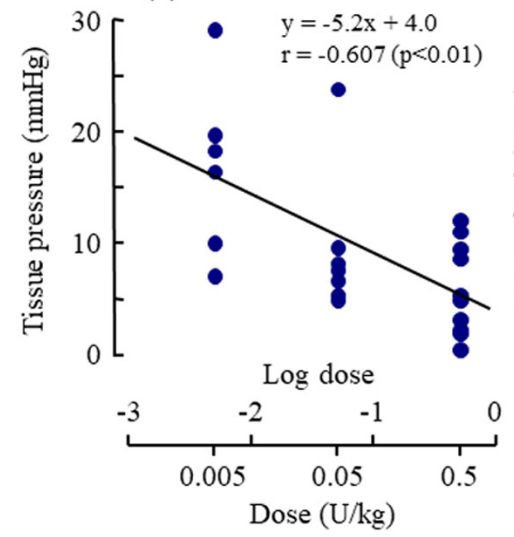

(y) (b)

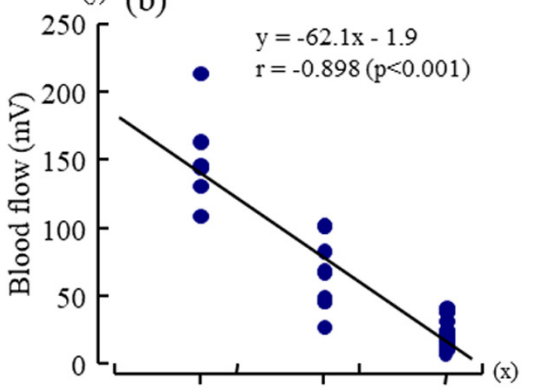

(d)

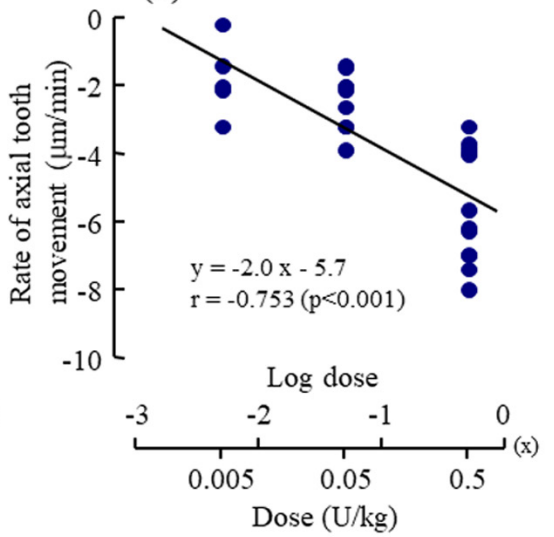

Figure 4: Dose-response effects of vasopressin (log dose $(\mathrm{U} / \mathrm{kg}), \mathrm{x})$ on

a) the maximum value of mean arterial blood pressure $(\mathrm{mmHg}, \mathrm{y})$,

b) the minimum value of regional blood flow $(\mathrm{mV}, \mathrm{y})$,

c) the minimum value of tissue pressure $(\mathrm{mmHg}, \mathrm{y})$, and

d) the minimum rate of axial tooth movement $(\mu \mathrm{m} / \mathrm{min}, \mathrm{y})$.

Each point represents the value from one animal following injection of a dose of vasopressin. The correlation coefficients (r) were significantly different from zero $(p<0.01 \sim 0.001$, $t$-test) for all of the regression lines. 
(a)

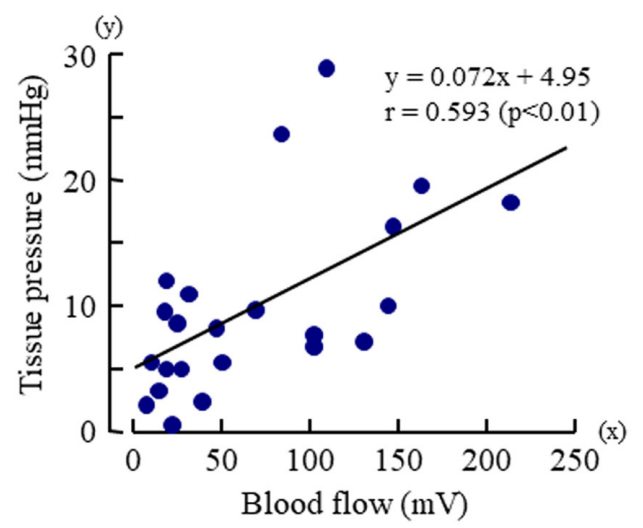

(b)

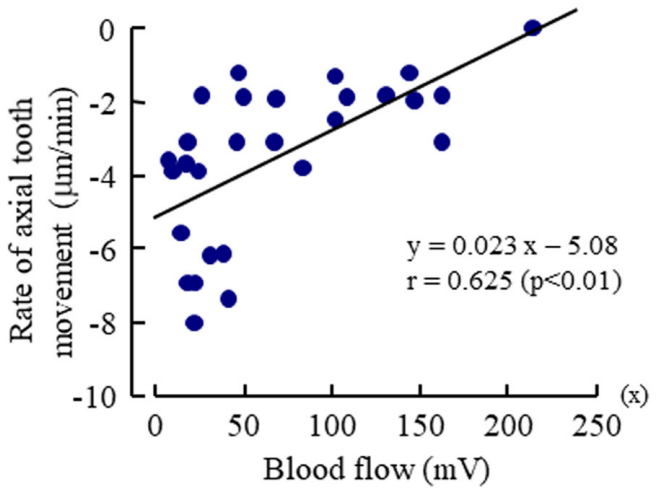

(c)

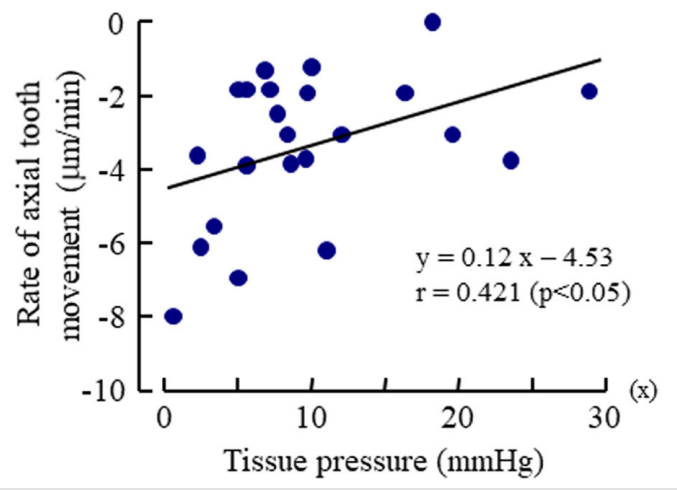

Figure 5:

a) Correlation between the minimum values of regional blood flow $(\mathrm{mV})$ and the minimum values of tissue pressure $(\mathrm{mmHg})$, b) correlation between the minimum rates of axial tooth movement $(\mu \mathrm{m} / \mathrm{min})$ and the minimum values of regional blood flow $(\mathrm{mV})$, and

c) correlation between the minimum rates of axial tooth movement $(\mu \mathrm{m} / \mathrm{min})$ and the minimum values of tissue pressure following injections of various doses of vasopressin.

Each point represents the value from one animal following injection of a dose of vasopressin. The correlation coefficients (r) were significantly different from zero ( $p<0.05 \sim 0.01$, $t$-test) for all of the regression lines. 

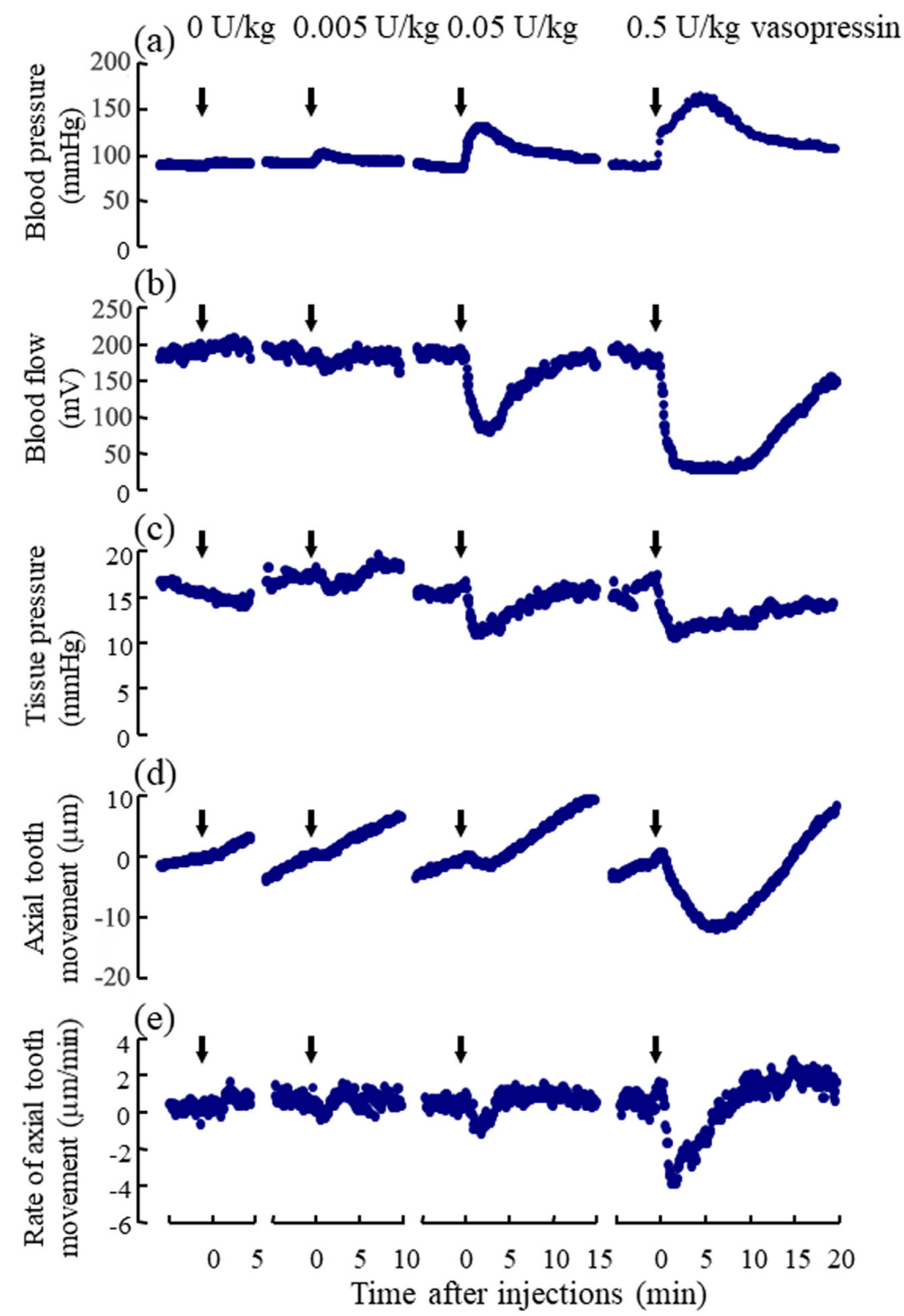

Suppl. Figure 1: Changes in the mean values of

a) arterial blood pressure $(\mathrm{mmHg})$,

b) regional blood flow $(\mathrm{mV})$,

c) tissue pressure $(\mathrm{mmHg})$,

d) axial tooth movement ( $\mu \mathrm{m})$, and

e) rate of axial tooth movement $(\mu \mathrm{m} / \mathrm{min}$ ) following the injections of vasopressin.

Arrows indicate the start of the injections of $0,0.005,0.05$, and $0.5 \mathrm{U} / \mathrm{kg}$ vasopressin, respectively. Each point respresents the mean of eight to fourteen rats at intervals of $6 \mathrm{~s}$.

\section{Discussion}

\section{Measurement of the Tissue Pressure in the Dental Pulp}

The servo-controlled micropressure measurement technique [8] combined with micropuncture pipette $[7,11,12]$ has been considered to be the most reasonable and reliable method for the direct measurement of tissue pressure within the tooth; this method is less traumatic than the previously used methods $[9,10]$. Here, we decalcified the exposed bone at the base of the incisor using etching agent and could then insert the glass microelectrode for measurement of tissue pressure through the bone into the dental pulp. The acidic agent for decalcification of the bone might have caused inflammation within the dental pulp. However, we could determine the dose-response effects of vasopressin on the blood flow and tissue pressure within the socket, and the axial tooth movements in fourteen animals and these signals after rinses between different drug doses returned to almost the same baselines. Thus, only a small area of the apical dental pulp appeared to be affected by inflammation. These inevitable effects seem to be small compared to the experimental marked responses against 
vasopressin. We were able to measure the tissue pressure in the dental pulp with less variations and less noises in the present study.

\section{Relevance of the Measurement of the Tissue Pressure in the Dental Pulp}

It is important to understand the physiological characteristics of the vasculature in and around the tooth in relation to the axial tooth movement. The dental pulp is a highly vascular tissue enclosed in rigid mineralized dentin $[17,18]$ blood vessels enter and exit the pulp via the apical and accessary foramina with nerve bundles, and its circulation lacks collateral circulation. The capillaries are present as two types: continuous capillaries and fenestrated capillaries [19]. The latter type of capillaries presents a thin endothelium layer exhibiting circular transcellular openings. Most fenestrated capillaries are found in the subodontoblastic plexus. The periodontal ligament of the rat teeth has a greater percentage of its capillary surface area occupied by fenestrations and contains a greater number of fenestrations per unit volume tissue [20]. The tissue fluid produced from such blood vessels in and around the tooth is one of the important physiological factors of the microvascular environment [17-20]. It has also been found that pulpal blood flow and tissue pressure simultaneously increased after electrical tooth stimulation, suggesting that vascular distension caused by the increased blood flow compresses the lowcompliance pulpal tissue [18-21]. In addition, the increases in the regional blood flow following local injection of acetylcholine and Ringer's infusion were observed in the rat incisor $[5,6]$. Thus, the vasoconstriction by vasopressin caused a decreased regional blood flow, leading to a decreased regional fluid volume within the tooth socket, which should have decreased the regional tissue pressure in the rigid enclosed dentin chamber $[7,17,18,22]$.

\section{Relationship between the Tooth Movement and the Tissue Pressure}

The present analysis showed the correlation of the axial movement and the tissue pressure within the socket as well as the correlation of the axial tooth movement and the blood flow within the socket (Figure5b \& 5c). Van Hassel and McMinn recorded the pressure $(10 \mathrm{mmHg})$ within erupted teeth and the pressure (23mmHg) within erupting teeth [9]. In recent studies, the tissue pressure values measured with the micro puncture technique were 5.5 and $9.9 \mathrm{mmHg}$ in cat and ferret dental pulp, respectively, and $15.2 \mathrm{mmHg}$ in the rat incisor periodontal ligament $[7,11,12]$. The present value (17.1 $\mathrm{mmHg}$, Suppl. Figure1S) of the tissue pressure in the dental pulp of the rat incisor by the same technique is like the last value. When the forces required to restrain the eruptive movements of the rat mandibular incisors under anesthesia were converted to pressures [23-25], the forces were calculated to be $10-15 \mathrm{mmHg}$. The tissue pressures are higher in the dental pulp and periodontal ligament of the erupting teeth than in those of the erupted teeth, suggesting a possible relation between the eruptive tooth movement and the tissue pressure.

\section{Conclusion}

The measurement of the tissue pressure as well as the blood flow in and around teeth is very useful to investigate into the relationship between the tooth movement and its vasculature.

\section{Conflict of interest}

The authors indicated no potential conflicts of interest.

\section{Acknowledgement}

This research was supported by research grants from the Society for the Tsurumi University School of Dental Medicine and from JSPS KAKENHI Grant Number JP18K09757.

\section{References}

1. Moxham BJ (1979) The effects of some vaso-active drugs on the eruption of the rabbit mandibular incisor. Arch Oral Biol 24(9): 681-688.

2. Aars H (1982) The influence of vascular beta-adrenoceptors on the position and mobility of the rabbit incisor tooth. Acta Physilol Scand 116(4): 423-428.

3. Cheek CC, Paterson RL, Proffit WR (2002) Response of erupting human second premolars to blood flow changes. Arch Oral Biol 47(4): 851-858.

4. Shimada A, Shibata T, Komatsu K (2004) Relationship between the tooth eruption and regional blood flow in angiotensin II-induced hypertensive rats. Arch Oral Biol 49: 427-433.

5. Shimada A, Komatsu K, Chiba M (2006) Effects of local injections of vasoactive drugs on eruption rate of incisor teeth in anesthetized rats. Arch Oral Biol 51: 449-456.

6. Shimada A, Komatsu K, Shibata T, Chiba M (2006) The effects of an intravenous infusion of Ringer's solution on eruption rates of incisor teeth in anaesthetized rats. Acta Odontol Scand 64: 16-20.

7. Heyeraas KJ, Berggreen E (1999) Interstitial fluid pressure in normal and inflamed pulp. Crit Rev Oral Biol Med 10(3): 328-336.

8. Wiederhielm CA, Woodbury JW, Kirk S, Rushmer RF (1964) Pulsatile pressures in the microcirculation of frog's mesentery. Am J Physiol 207: 173-176.

9. Van Hassel HJ, McMinn RG (1972) Pressure differential favouring tooth eruption in the dog. Arch Oral Biol 17: 183-190.

10. Walker TW, Ng GC, Burke PS (1978) Fluid pressures in the periodontal ligament of the mandibular canine tooth in dogs. Arch Oral Biol 23: 753765.

11. Kristiansen AB, Heyeraas KJ (1989) Micro puncture measurements of interstitial fluid pressure in the rat periodontal ligament. Proc Fin Dent Soc 85: 295-300.

12. Jacobsen EB, Heyraas KJ (1997) Pulp interstitial fluid pressure and blood flow after denervation and electrical tooth stimulation in the ferret. Arch Oral Biol 42: 407-415.

13. Chiba M (1994) Possible role of the periodontal ligament and vasculature in axial movements of the rat incisor. The biological mechanisms of tooth eruption, resorption and replacement by implants. Boston, MA: Harvard Society for the Advancement of Orthodontics. pp. 459-466.

14. Moxham BJ, Berkovitz BKB (1995) The periodontal ligament and physiological tooth movements. The periodontal ligament in health and disease. Second Edition. London, UK: Mosby-Wolfe pp. 183-214.

15. Chiba M, Komatsu K, Yamaguchi S (1995) Axial movements of rat mandibular incisors measured under artificial respiration with halothane anaesthesia. Arch Oral Biol 40: 269- 274.

16. Kurauchi Y, Mokudai K, Mori A, Sakamoto K, Nakahara T, et al. (2017) L-Citrulline ameliorates cerebral blood flow during cortical spreading 
depression in rats: Involvement of nitric oxide- and prostanoidsmediated pathway. J Pharmacol Sci 133: 146-155.

17. Bletsa A, Berggreen E, Fristad I, Tenstad O, Wiig H (2006) Cytokine signaling in rat pulp interstitial fluid and transcapillary fluid exchange during lipopolysaccharide-induced acute inflammation. J Physiol 573 225-236.

18. Heyraas KJ, Kim S, Raab WH-M, Byers MR, Liu M (1994) Effect of electrical tooth stimulation on blood flow, interstitial fluid pressure and substance-P and CGRP- immunoreactive nerve fibres in the lowcomplianct cat dental pulp. Microvasc Res 47(3): 329-343.

19. Frank RM, Nalbandian J. Structure and ultrastructure of the dental pulp. Handbook of Microscopic Anatomy Volume 6 Teeth. Berlin: SpringerVerla pp. 287-295.

20. Moxham BJ, Shore RC, Berkovitz BKB (1985) Fenestrated capillaries in the connective tissues of the periodontal ligament. Microvasc Res 30: 116-124.

ISSN: 2574-1241

DOI: 10.26717/BJSTR.2019.24.003991

Koichiro Komatsu. Biomed J Sci \& Tech Res

(C) This work is licensed under Creative

Submission Link: https://biomedres.us/submit-manuscript.php
21. Berggreen E, Heyeraas KJ (1999) The role of sensory neuropeptides and nitric oxide on pulpal blood flow and tissue pressure in the ferret. J Dent Res 78: 1535-1543.

22. Kim S (1985) Regulation of pulpal blood flow. J Dent Res 64 (Spec Iss): 590-596.

23. Chiba M, Yamaguchi S, Komatsu K (1996) Measurement of the force needed to restrain eruptive movement of the rat mandibular incisor Arch Oral Biol 41: 341-349.

24. Shimada A, Shibata T, Komatsu K, Chiba M (2003) The effects of intrusive loading on axial movements of impeded and unimpeded rat incisors: estimation of eruptive force. Arch Oral Biol 48(5): 345-351.

25. Ness AR (1964) Movement and forces in tooth eruption. Advances in oral biology, London (UK): Academic Press pp. 33-75.

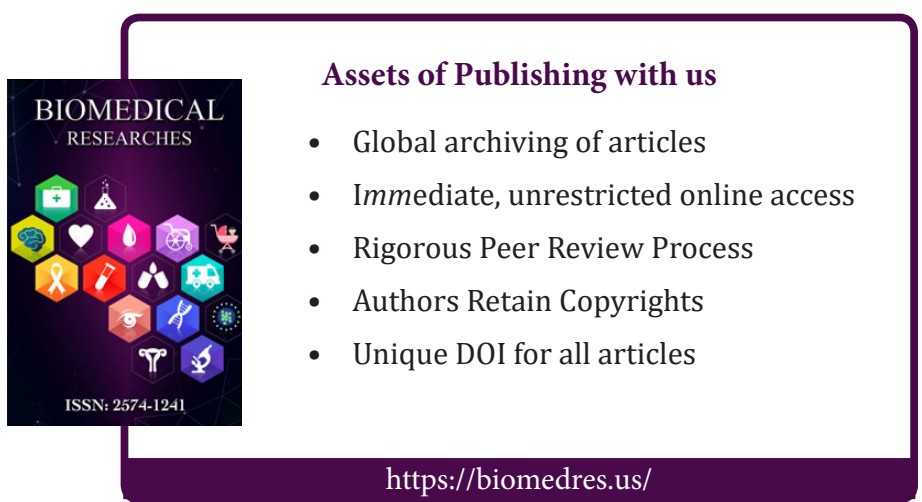

